\title{
Conspectus: Inventing Futures for the Rhetoric of Science, Technology, and Medicine
}

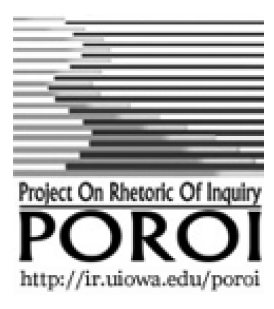

\section{Challenges and Opportunities}

\author{
Lisa Keränen \\ Department of Communication, University of Colorado Denver
}

Poroi 9,1 (April 2013)

The future is already here. It's just not evenly distributed yet. -William Gibson (as quoted in Kennedy, 2012, p. BR1).

The purpose of this special issue of $P O R O I$ is to stimulate conversation about the inventional resources for scholarship concerning the rhetoric of science, technology, and medicine (RSTM). ${ }^{1}$ Invention, the "process and art of creation, discovery, and problem solving," has comprised a central concept in the rhetoric of science and technology from its earliest days (Young, 1996, p. 349; see, e.g., Campbell \& Benson, 1996; Gross \& Keith, 1996; Harris, 1997; Miller, 1985; Prelli, 1989; Simons, 1990). For instance, writing in the fourth issue of Philosophy \& Rhetoric in 1975, James Stephens invoked Albert Einstein on the creative elements of knowledge formation in science. For Einstein, knowledge "can grow only from "comparison of the inventions of the intellect with observed fact" (Stephens, 1975, p. 213). By examining Einstein's comments about how Johannes Kepler used analogical reasoning and Christian symbolism to persuade his contemporaries about science, Stephens called attention to invention in matters of "scientific presentation" (p. 213). Many rhetoricians of science, technology, and medicine see invention as playing a deeper role than mere presentation, however. In this view, invention underpins the discovery of knowledge itself (see, e.g., Baake, 2003; Lauer,

${ }^{1}$ The most common description of this disciplinary subfield is the "rhetoric of science," to which "and technology" is sometimes added. The recent proliferation of rhetorical studies that address health and medical discourses has led some to add "medicine" to the list. However, as one ARST member recently made clear to me, not all rhetoricians of science are comfortable extending the moniker. Some believe adding the term "medicine" makes an already small subfield too diffuse. Nonetheless, ARST benefits from maintaining strong connections with rhetoricians who study health and medicine. As editor of this special issue, I was struck by the diverse array of labels that different authors used to characterize the subjects of our work. In nearly all cases, I preserved the authors' original terms and acronyms. 
2004). As David Depew and John Lyne suggest, invention "is a process of discovery and proof" (this issue, emphasis original). By highlighting the role of invention in our own practice, this issue asks us to consider the emerging trajectories of RSTM scholarship and practice.

This special issue originated with the 2012 annual meeting of the American Association for the Rhetoric of Science and Technology (ARST), held jointly with the National Communication Association (NCA) at the Swan Resort in Orlando, Florida, on November 14, 2012. There, a congenial group of emeritus faculty, current faculty, instructors, and graduate students assembled for a day-long preconference, "Inventing the Future: The ARST Vicentennial Celebration," in order to commemorate the twentieth anniversary of the association and to deliberate about where the field was headed. ${ }^{2}$ The aim of the preconference was "to unite multiple generations of rhetoric of science and technology scholars in a conversation about the inventional potential of the rhetoric of science, technology, and medicine" (ARST, 2012). As the preconference organizer, I invited leading scholars to draft position and response papers reflecting on our origins and possible futures. I also asked scholars to serve as conversational co-anchors for a series of Octavian tables intended to spark discussion about future lines of inquiry in six key areas: scientific genres; the rhetoric of technology; the rhetoric of medicine and health; visual rhetorics of science; science, publics, and controversy; and nanotechnology and synthetic biology. Revisions of the original position and response papers-along with post-conference reflections from the leaders of each of the Octavian tables-appear in this issue.

The first set of papers and responses featured in this special issue derive from the panel discussion, "What's In Our Repertoire?” I invited the panelists to reflect on "how existing work in the rhetoric of science and technology may afford resources for thinking about, or engaging in, rhetorical invention" and asked them to "revisit past work with an eye toward finding inventional possibilities" (ARST, 2012). The section opens with Lawrence J. Prelli on “The Prospect of Invention.” Prelli outlines three lines of inquiry for future scholarship: the creative invention of perspectives in science, technology, and medicine; the analysis of the commonplaces of "expert" discourses; and the identification of the unique contributions of a rhetorical perspective in transdisciplinary projects. Celeste M. Condit urges rhetoricians interested in science, technology, and medicine to turn their attention to the gaps in our scholarship. She nudges scholars toward international studies and asks us to be mindful of our own biases, particularly the tendency among some rhetoricians of science and technology to be more critical of science than they are of those who seek to undermine higher education's charge to acquire knowledge. David Depew and John Lyne map the existing terrain of rhetorical studies of science, technology, and medicine, arguing that the standard resources of the rhetorical tradition contain much unused inventional potential. Responding to the papers from this panel, John

${ }^{2}$ I invented the term "Vicentennial," because existing terms for twentieth anniversary, "Vicennial" and "Vigintennial," lacked the appropriate ring. For a record of the day's events, visit http://arstvicentennial.weebly.com. 
Angus Campbell explores their resonances and tensions, while Jeanne Fahnestock provides alternate mappings and outlines many of the challenges facing ARST.

Authors of the second set of papers and responses were charged with "focus[ing] on emerging work, collaborative projects, and the developing possibilities for shaping discourse and discursive understanding in the rhetoric of science, technology, and medicine" (ARST, 2012). This panel, "Horizons of Possibility," aimed to "take seriously the idea that there is a repertoire to be drawn upon, updated, or deployed in order to provide resources for invention" and to "consider recent venues of research or public intervention as places where renewed attention to invention might produce creative responses" (ARST, 2012). Reflecting this charge, Leah Ceccarelli examines recently published RSTM research and inquires about the audiences for and purposes of our work. Ceccarelli urges us to find ways to make our scholarship more accessible to its wider stakeholders. In the next paper, Randy Allen Harris argues for a cognitive rhetoric of science. Drawing on contemporary cognitive research along with the insights of Kenneth Burke and Jeanne Fahnestock, Harris seeks to connect cognitive rhetoric to the rhetoric of science. Then, Carl Herndl and Lauren Cutlip advance a vision for large-scale, interdisciplinary, collaborative, problem-based research that draws from emerging theoretical perspectives and science studies. In response, Lynda Walsh counters with a horizon myth of her own, while Carolyn R. Miller-expressing some unease with a number of the positions articulated in the papers-raises important questions about our identity. While the first set of papers provides insightful mappings of extant and possible future RSTM research, this second set furnishes a rousing debate about where the field is heading and why.

The third set of papers reflects on emerging directions in RSTM special topics. These short essays were developed from the Octavian roundtable discussions, in which participants were tasked with discussing future lines of inquiry in their assigned topic area. Carolyn R. Miller and Jeanne Fahnestock open the section by discussing possible scholarly endeavors related to scientific and technical genres. Next, John Lynch and William J. Kinsella consider the entailments of studying the rhetoric of technologies, while Lawrence J. Prelli and Celeste M. Condit address the importance of visual rhetoric and visualization to the rhetoric of science, technology, and medicine. James Wynn and Lynda Walsh's essay about studying scientific controversies considers how rhetoricians can extend our understanding of the relations between science and its stakeholders. Then, David M. Berube sketches potential scholarly inquiries into the "fringe science" topics of nanotechnology, geoengineering, and synthetic biology. Finally, J. Blake Scott, Judy Z. Segal, and Lisa Keränen outline areas of inquiry in the rhetorics of health and medicine. This third set of essays advances an agenda that should prove especially useful for graduate students and newcomers to the field. This section also serves as a useful marker of where scholars saw RSTM scholarship heading in the second decade of the twenty-first century. When considered as a whole, however, the essays across all three 
sections reveal a number of challenges and opportunities facing the RSTM community.

\section{Four Questions and Some Possible Futures for the Field}

John Angus Campbell describes the conversation recorded in the pages of this special issue of $P O R O I$ as representing "a stimulating set of proposals, a daunting set of problems, and some varied and potentially fruitful inventional resources" (this issue). To be sure, there is cause for excitement about the growth of RSTM scholarship. The number of books about RSTM continues to rise. Leah Ceccarelli's informal survey of academic essays appearing in the early months of 2012 led her to conclude that "rhetoricians of science and technology are publishing an impressive amount of scholarship"-23 essays across 13 separate venues, in fact (this issue)! Yet, the conversation reflected herein reveals four interrelated questions-each bearing an associated set of challenges and opportunities-for those who study RSTM.

\section{What are the Purposes of RSTM Scholarship and Practice?}

This special issue reveals considerable disagreement about the purposes of our scholarly inventions. Celeste M. Condit explicitly laments a perceived lack of reflection about the aims of RSTM scholarship, while Jeanne Fahnestock notes that "rhetoricians have not been clear in defining the distinctive contribution of their approach" (this issue). In particular, Randy Allen Harris reminds us that "there are prominent, divergent courses between the impulse to understand persuasion and the impulse to achieve persuasion, and those two motives date to the very first writings in the field"(this issue, original emphasis). This tension between "the curriculum vitae contemplativum and the cv activum," as Carolyn R. Miller describes it (this issue, original emphasis), bears consequences for how we conduct and evaluate our scholarly efforts. As timely as the calls for engagement in contemporary academia may be, many among us are not convinced that our future lies in public intellectualism. Reflecting on this tension, Lynda Walsh succinctly asks, "how do we achieve greater disciplinary rigor without losing our civic edge, and how do we make ourselves a public resource without becoming a tool of hegemony?" (this issue). Given its origins in the earliest debates of our field, it is unlikely that we will resolve the tension between understanding and engagement in the near future. Raising the issue is important, however, for as Fahnestock observes, "how we define the nature and contribution of RSTM determines how we present ourselves to other disciplines in the academy, to the scientific community, and to the public" (this issue). In other words, there are significant stakes involved in how we conceive of the aims of our RSTM scholarship and practice, not only for ourselves but also for the potential partners and stakeholder groups who would benefit from our work. 


\section{Who Are the Audiences for RSTM Work? And How Can We Strengthen Our Relationships with Our Academic and Public Stakeholders?}

Fahnestock's observation, like Walsh's question, points to a second, closely related tension concerning RSTM scholars' relationships with various other academic specialties and with the broader constituencies who might benefit from our work. Making a point about our lack of disciplinary influence in allied academic areas, Fahnestock echoes a previously raised concern (see, e.g., Gross, 2006) that "scholars in related fields do not routinely access or acknowledge rhetorical studies"

(Fahnestock, this issue). Moreover, as she demonstrates, some colleagues in other fields still see rhetoric in negative terms. If our low interdisciplinary influence, in part based on a misunderstanding of our key term, is one challenge facing RSTM scholars, then an additional challenge concerns our relationships with broader stakeholders of our work. Ceccarelli underscores this second challenge when she observes that "we have no established apparatus to facilitate the translation of that most valued academic work to the empowered stakeholders who could benefit from it" (this issue). Fahnestock and Ceccarelli's comments indicate that rhetoricians of science, technology, and medicine could simultaneously do more to reach other science and science studies scholars and to make our work more accessible to the broader, often nonacademic stakeholders who are and who might be impacted by our research and practice. John Angus Campbell (this issue) seeks to answer these dual charges through a focus on "democratic demarcations" that "nurture personal, public and technical sphere contexts in which reasoned deliberation about science and its implications can occur." The authors in this issue advance different solutions for reaching, and in some cases partnering with, broader audiences and stakeholders, but perhaps rhetoricians of science, technology, and medicine are not taking full advantage of the mechanisms for engagement and translation that have been developed by colleagues in other parts of Communication, English, and cognate disciplines (see, e.g., Frey \& Carragee, 2007a,b). ARST should arguably devote time at future meetings to consider these important questions of audience and engagement and to discuss the interrelated question of purpose.

\section{How Do We Orient Ourselves Theoretically in a Post-Modern, Risk-Filled World?}

Beyond debates about the purposes of our scholarship and our often vexed relations with other academic and public stakeholders, this special issue evidences a tension between modernist, textualist approaches to RSTM and non- or even post-modern, post-human approaches that stress materiality and practice. Some ARST members are increasingly orienting themselves toward addressing the perceived risks and pressing problems facing the planet. Herndl and Cutlip, for instance, argue that the field is moving from a "modern and humanist" orientation toward a "nonmodern and post-human" focus, and they observe that this shift necessarily alters "our dominant theory of realism, our understanding of 
agency, and the location where we do our work" (this issue). Not all ARST members desire to work in a post-human, ontological idiom (Mol, 2003), however, even as epistemology and ontology are not mutually exclusive. Nonetheless, materiality, as contrasted with symbolicity, occupies an increasingly prominent role in other humanities and social science disciplines, and rhetoricians of all stripes-especially rhetoricians of science, technology, and medicine-will benefit from making connections with these larger academic discourses.

\section{What are the Appropriate Methods for Scholarship in the Rhetoric of Science, Technology, and Medicine?}

Closely related to the questions concerning our theoretical approach are questions concerning method-questions that have spurred recurrent conversations in the rhetorics of health and medicine, which has, in recent years, taken an increasingly, but not exclusively, ontological and social science turn. Some of the authors in this issue repeatedly stress the "unique," "distinctive" nature of the rhetorical tradition, even arguing, as do Depew and Lyne (this issue), that there is much untapped potential in the rhetorical toolbox (see Prelli, this issue). Others, such as Herndl and his students, want to draw from and contribute to a wider, extrarhetorical, and sometimes social scientific corpus. Still others call for an expansion of the traditional rhetorical toolbox to a broader consideration of theories and concepts that would enhance our understanding of biomedical, technical, and scientific networks, assemblages, and movements (Scott, Segal, \& Keränen, this issue). Even as they advocate for a certain kind of expansion, Scott, Segal, and Keränen identify the dilemma inherent in this trend. "One challenge in looking beyond the traditional rhetorical toolbox," they explain, "is how to utilize the methods of social science in ways that leverage our uniquely rhetorical contributions" (this issue). As Prelli (this issue) asserted, "content analysis, interviews, and ethnography do not distinguish what rhetoricians bring uniquely to cross-disciplinary projects.” As we move forward as a field, rhetoricians of science, technology, and medicine will need to find ways to make a stronger case for our identity and importance, especially as we try to reach wider audiences and to build broader alliances.

\section{Possible Futures: Trajectories and Opportunities}

Invention marks potentialities, signaling places for further growth. The significant questions outlined above notwithstanding, rhetoricians of science, technology, and medicine face an ever-expanding array of potential issues in a time of pressing planetary need. The conversation reflected in these pages charts many lines of inquiry and engagement that can animate RSTM scholarship in the coming years. Three in particular stand out: visual rhetorics, digital communication, and the interplay among science, technology, medicine and their globalized publics. A number of the essays, position papers, and Octavian table reports designated visual rhetoric and visualizations in science as an important emerging area. Additionally, authors repeatedly identified the affordances 
of the Internet and digital technologies (and their impact on science, technology, and medicine) as avenues for future inquiry in areas ranging from genre studies through the rhetorics of health and medicine. Finally, a number of scholars pointed to the significance of scholarship that addresses the interface between publics and science, technology, and medicine. These three areas represent but a few of the many possible growth areas for RSTM scholarship that are highlighted herein.

Beyond expansion of these topical areas, the questions raised in this special issue present unique opportunities for rhetoricians of science, technology, and medicine to begin to reimagine our possible identities and relationships. In that way, Condit, Herndl, Harris, Ceccarelli, Prelli, and the other authors in this special issue illuminate potential future personae for ARST scholars. The questions raised in this special issue further suggest that RSTM scholars would benefit from having a series of discussions about how we might re-envision our scholarly purposes and practices in light of the challenges raised herein. Globalization and engagement should arguably figure prominently in such discussions. Whatever paths our future inquiries take, whatever personae we invent, ARST and the Project on the Rhetoric of Inquiry (POROI) should play leading roles in facilitating conversations about the future of RSTM.

\section{Acknowledgements and Resources}

This special issue was nurtured by the ARST community and by POROI at the University of Iowa. Special thanks to the ARST board of governors, its past leaders, and its current officers, especially David Berube, David Depew, John Lynch, John Lyne, Karen Taylor, Greg Wilson, and James Wynn, for talking through the inventional process for the preconference. John Lyne made the original suggestion to focus on invention and helped craft the framing language, while David Depew suggested the Octavian table format that animated our afternoon discussions. As associate editors, Allison Dietz, Jennifer Malkowski, and William White deserve gratitude for taking the first pass at editing and formatting the manuscripts and for helping to re-check them. A Dean's Fund for Excellence Grant from the College of Liberal Arts and Sciences (CLAS) at the University of Colorado Denver provided research and editorial assistance. Henry (Harry) Archer assisted with manuscript formatting, while S. Scott Graham and Lawrence J. Prelli provided helpful feedback. Stephen John Hartnett, as always, provided domestic support, patience, and good humor. At POROI, the ever helpful Managing Editor, André Brock, and the highly efficient Administrative Assistant and Webmaster, Scott Siegling, processed and converted the manuscripts to their electronic format through many extended email exchanges, while David Depew cheered us on at every stage of the process.

To coincide with the preconference, ARST launched an oral history project that has produced videos of interviews with leading ARST scholars. Damien Smith Pfister deserves credit for his diligent leadership of this project; he was assisted by Jennifer Malkowski, Kenny Walker, and video editor Carrie Adkisson. Hoofta Productions donated the lighting equipment. The videos can be accessed at http://www.youtube.com/ user/ARSTonline or through the ARST website at http://arstonline.org. 
The interview videos supplement this special issue by providing teaching resources for those interested in the rhetoric of science, technology, and medicine. At the time this issue went to press, interviews with John Angus Campbell, Leah Ceccarelli, and Celeste Condit were accessible online. Interviews with many of the other authors whose essays appear in this issue will be released in the coming months.

I hope readers will see, as William Gibson asserted in the epigraph, that the future, in many ways, already appears in the present. This special issue offers a reflection on the past and the present as well as a glimpse into the various tensions and the possible future trajectories for RSTM scholarship and practice. May the conversations from the 2012 ARST anniversary celebration recorded in this special issue of POROI continue.

\section{References}

ARST. (2012). Inventing the future: ARST vicentennial preconference. Accessed April 3, 2013. http://www.arstvicentennial.weebly.com

Baake, K. (2003). Metaphor and knowledge: The challenges of writing science. Albany, NY: SUNY Press.

Campbell, J. A., \& Benson, K. R. (1996). The rhetorical turn in science studies. Quarterly Journal of Speech, 82, 74-109.

Frey, L. R., \& Carragee, K. M. (Eds.). (2007a). Communication activism: Volume 1. Communication for social change. Cresskill, NJ: Hampton Press.

Frey, L. R., \& Carragee, K. M. (Eds.). (2007b). Communication activism: Volume 2. Media and performance activism. Cresskill, NJ: Hampton Press.

Gross, A. G. (2006). Starring the text: The place of rhetoric in science studies. Carbondale, IL: Southern Illinois University Press.

Gross, A. G., \& Keith, W. M. (Eds.). (1996). Rhetorical hermeneutics: Invention and interpretation in the age of science. Albany, NY: SUNY Press.

Harris, R. A. (Ed.). (1997). Landmark essays in the rhetoric of science: Case studies. Mahwah, NJ: Lawrence Erlbaum.

Kennedy, P. (2012, January 13). Rewiring reality: William Gibson's future is now. New York Times (Sunday Book Review), BR1.

Lauer, J. M. (2004). Invention in rhetoric and composition. West Lafayette, IN: Parlor Press.

Miller, C. (1985). Invention in scientific and technical discourse: A prospective survey. In M. G. Moran \& D. Journet (Eds.), Research in technical communication: A bibliographic sourcebook (pp. 117-162). Westport, CT: Greenwood Press.

Mol, A. (2002). The body multiple: Ontology in medical practice. Durham, NC: Duke University Press. 
Prelli, L. J. (1989). A rhetoric of science: Inventing scientific discourse. Columbia: University of South Carolina Press.

Simons, H. W. (Ed.). (1990). The rhetorical turn: Invention and persuasion in the conduct of inquiry. Chicago, IL: University of Chicago Press.

Stephens, J. (1975). Rhetorical problems in Renaissance science. Philosophy \& Rhetoric, 8(4), 213-229.

Young, R. E. (1996). Invention. In T. Enos (Ed.), Encyclopedia of rhetoric and composition: Communication from ancient times to the information age (pp. 349-353). New York: Garland. 